\title{
Theoretical Explanation for Reduced Body Mass Index and Obesity Rates in Cannabis Users
}

\author{
Thomas M. Clark, Jessica M. Jones, Alexis G. Hall, Sara A. Tabner, and Rebecca L. Kmiec
}

\begin{abstract}
Introduction: Obesity is treatment-resistant, and is linked with a number of serious, chronic diseases. Adult obesity rates in the United States have tripled since the early 1960s. Recent reviews show that an increased ratio of omega- 6 to omega-3 fatty acids contributes to obesity rates by increasing levels of the endocannabinoid signals $A E A$ and $2-A G$, overstimulating $C_{1} R$ and leading to increased caloric intake, reduced metabolic rates, and weight gain. Cannabis, or $T H C$, also stimulates $\mathrm{CB}_{1} \mathrm{R}$ and increases caloric intake during acute exposures.

Goals: To establish the relationship between Cannabis use and body mass index, and to provide a theoretical explanation for this relationship.

Results: The present meta-analysis reveals significantly reduced body mass index and rates of obesity in Cannabis users, in conjunction with increased caloric intake.

Theoretical explanation: We provide for the first time a causative explanation for this paradox, in which rapid and long-lasting downregulation of $\mathrm{CB}_{1} \mathrm{R}$ following acute Cannabis consumption reduces energy storage and increases metabolic rates, thus reversing the impact on body mass index of elevated dietary omega-6/omega3 ratios.
\end{abstract}

Keywords: Cannabis; body mass index; obesity; omega-6 fatty acid; theory

\section{Introduction}

The current review and meta-analysis establishes the impact of Cannabis use on body mass index (BMI) and obesity rates, and provides a well-supported physiological, causative explanation for this impact. Cannabis use appears to reverse the impact of the modern American diet on health by reducing the effects of an elevated ratio of omega-6/omega- 3 fatty acids on endocannabinoid (eCB) tone. It is therefore necessary to understand how diet impacts health to understand the health impact of Cannabis use.

Diet is the main cause of premature death and disability in the United States. The modern western diet is proinflammatory and obesogenic. ${ }^{1,2}$ Diseases associated with inflammation and obesity include cancer, cardiovascular disease, diabetes mellitus (DM), Alzheimer's dis- ease, mood disorders, autoimmune disorders, liver and kidney disease, and musculoskeletal disabilities. ${ }^{1-12}$ A significant dietary factor contributing to these health problems is an increased ratio of omega- 6 (linoleic acid, LA) to omega-3 ( $\alpha$-linolenic acid, ALA) fatty acids, ${ }^{2,10,13-21}$ especially in the context of a high glycemic load and reduced physical activity.

Recent reviews show that dysregulation of the eCB system plays a major role in development of obesity and metabolic disorders, and strongly implicate the elevated omega-6/omega-3 ratio as a primary cause of this dysregulation. ${ }^{15,18,19,22-29}$ Omega-6 fatty acids are precursors of the eCBs $\mathrm{N}$-arachidonoylethanolamide (AEA, or anandamide) and 2-arachidonoylglycerol (2$A G)$. These eCB signals act via receptors, including $\mathrm{CB}_{1} \mathrm{R}$ and $\mathrm{CB}_{2} \mathrm{R}$, and $\mathrm{CB}_{1} \mathrm{R}$ plays a primary role in energy

Department of Biological Sciences, Indiana University South Bend, South Bend, Indiana.

*Address correspondence to: Thomas M. Clark, PhD, Department of Biological Sciences, Indiana University South Bend, South Bend, IN 46634, E-mail: tclark2@iusb.edu This article has been posted in preprints.org but has not been submitted to another peer-reviewed journal. The theory was presented at the Cannabis Learn Conference and Expo, Philadelphia, May 2, 2018.

(c) Thomas M. Clark et al. 2018; Published by Mary Ann Liebert, Inc. This Open Access article is distributed under the terms of the Creative Commons License (http://creativecommons.org/licenses/by/4.0), which permits unrestricted use, distribution, and reproduction in any medium, provided the original work is properly cited. 
homeostasis. An elevated dietary omega-6/omega-3 ratio therefore leads to elevated levels of AEA and 2-AG, overstimulation of $\mathrm{CB}_{1} \mathrm{R}$, and dysregulation of energy homeostasis leading to weight gain. ${ }^{21-23,25,29-32}$

\section{Metabolic consequences of the modern western diet}

Among the defining features of the modern western diet are a superabundance of calories from sugars and refined starches leading to increased glycemic load, and a strongly elevated ratio of omega- 6 to omega- 3 polyunsaturated fatty acids. The dietary omega-6/omega-3 ratio in hunter-gatherers is estimated to be around 1:1 to $3: 1$, whereas the ratio in the modern western diet is as high as 20:1 or more. ${ }^{2,13,16,18,19}$ This shift in dietary fatty acids increased sharply as more vegetable oils (especially soybean oil) and grains were incorporated into the diet. Corresponding with these changes in diet, rates of obesity and metabolic syndrome are increasing rapidly. ${ }^{14}$

Obesity is a major health concern, strongly associated with systemic inflammation and metabolic syndrome, with increased risk of DM, a variety of cancer types, cardiovascular disease, autoimmune disorders, anxiety, depression, Alzheimer's disease, and other serious medical conditions. ${ }^{3,7,8,11,18,33-36}$ Dietary dysregulation of the eCB system is emerging as a primary cause of these conditions, suggesting that therapeutic interventions targeting this system should be investigated as a primary way to reduce or eliminate many of the most serious chronic diseases characteristic of modern western societies.

\section{Overview of the eCB system}

The eCB system is a signaling system with a prominent role in homeostasis, and is reviewed extensively elsewhere. $^{15,22,23,25,26,28,37}$ This signaling system occurs within the central nervous system (CNS) and in multiple peripheral organs.

The eCB system involves signals and receptors. The main signals are AEA and 2-AG. A major biosynthetic pathway for each begins with the omega- 6 fatty acid (FA), LA, and proceeds through arachidonic acid. From arachidonic acid, multiple pathways and enzymes lead to AEA and 2-AG. AEA and 2-AG act through multiple receptors. Best-known are $\mathrm{CB}_{1} \mathrm{R}$ and $\mathrm{CB}_{2} \mathrm{R}, \mathrm{G}$ protein-coupled receptors that are located in the CNS, as well as peripherally on a variety of organs and tissues, including the gut, liver, bones, skeletal muscle, and adipose tissues. The eCB signals AEA and 2-AG are degraded by enzymes, primarily fatty acid amine hydrolase for AEA and other fatty acid ethano- lamides, and monoacylglycerol lipase for 2-AG and other monoacylglycerols. ${ }^{15,22,23,25,26,37-40}$

\section{Impact of the dietary omega-6/omega-3 ratio}

on the eCB system

Recent reviews suggest that disruption of the eCB system by an elevated omega-6/omega- 3 ratio contributes strongly to the metabolic dysregulation associated with the modern western diet. ${ }^{15,18,19,22-30,41,42}$ Elevated production of the eCBs AEA and 2-AG is central to the health problems associated with the elevated omega- 6 / omega-3 ratio. Omega- 6 FAs are converted to the eCB signals AEA and 2-AG. Therefore, the elevated omega-6/omega-3 ratio results in increased synthesis of AEA and 2-AG, resulting in overstimulation of $\mathrm{CB}_{1} \mathrm{R}$ (Fig. 1). Elevated $\mathrm{CB}_{1} \mathrm{R}$ activity in turn directly causes excess intake, storage, and conservation of energy leading to disruption of body mass and adipose tissue homeostasis. ${ }^{10,18,19,22,23,25,28-32,41-46}$

Omega-3 fatty acids are receiving considerable attention as dietary supplements due to their apparent ability to reduce obesity, inflammation, and associated chronic diseases. Their actions, at least in part, stem from their competition with omega- 6 fatty acids for shared enzymes (elongases and $\Delta$ desaturases, which are limiting), leading to reduced AEA and 2-AG levels and $\mathrm{CB}_{1} \mathrm{R}$ activity. Because of this competition, it is the ratio between the two groups of fatty acids rather than the absolute amount that is key for energy homeostasis. $4,10,12,15,17-22,47-50$

Role of eCB and $\mathrm{CB}_{1} \mathrm{R}$ in obesity

and metabolic disorders

$\mathrm{CB}_{1} \mathrm{R}$ is a primary mediator of energy uptake, storage, and conservation. It acts to maximize energy uptake and conservation through multiple mechanisms. Stimulation of $\mathrm{CB}_{1} \mathrm{R}$ modulates taste and smell pathways to increase the palatability of food. It stimulates the appetite centers of the brain, leading to hyperphagia and favoring fat accumulation in adipose tissue. At the same time, peripheral eCBs play a major role in regulating appetite, are influenced by the western diet, and AEA reduces energy expenditures, including energy expenditures during sleep. ${ }^{10,18,22,23,25,28,29,31,32,39,43-46,51-53}$.

These actions contribute to homeostasis in the context of a hunter-gatherer diet of plants, plant-feeding animals, and fish. However, the modern industrial western diet, characterized by an elevated omega-6/ omega-3 ratio, ${ }^{16}$ leads to chronic overstimulation of $\mathrm{CB}_{1} \mathrm{R}^{19,22,23}$ When combined with the elevated 


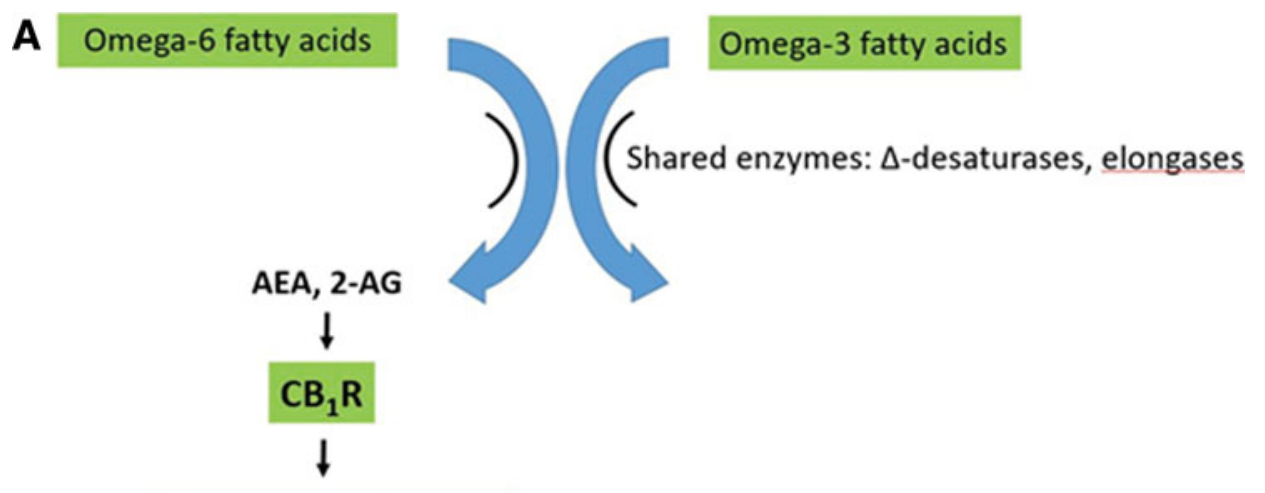

Healthy body mass

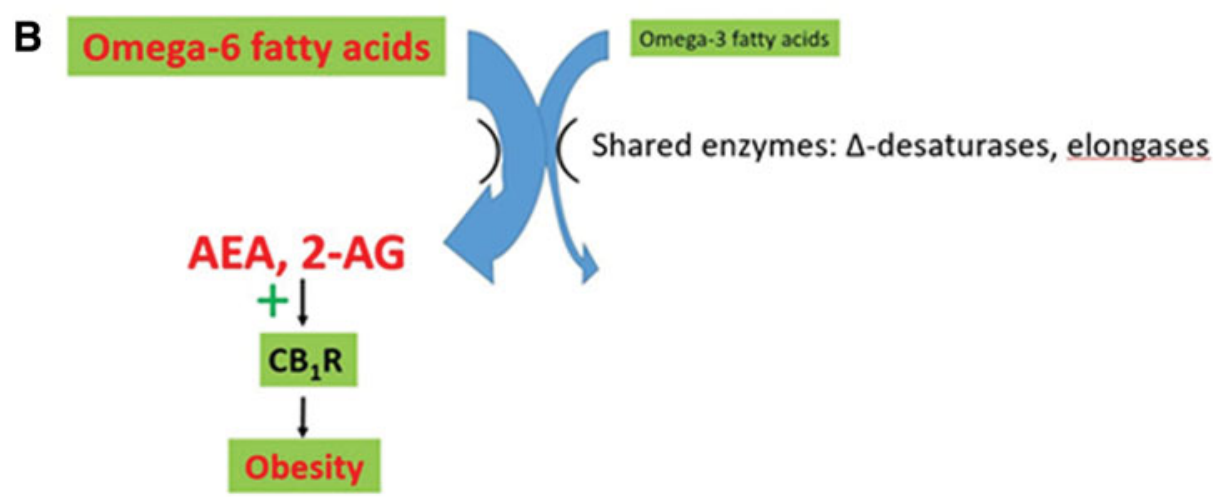

FIG. 1. The impact of the modern western diet on the endocannabinoid system. (A) In the presence of a natural omega-6/omega-3 ratio, production of the endocannabinoid signals AEA and 2-AG and resulting stimulation of CB1R are compatible with a healthy BMI. (B) The modern western diet, with its elevated omega-6/omega-3 ratio, leads to excess production of $A E A$ and $2-A G$. This overstimulates $C B_{1} R$, leading to weight gain and metabolic dysregulation. Modified from Freitas et al. (22). AEA, anandamide; $\mathrm{N}$-arachidonoylethanolamide; 2-AG, 2-arachidonoylglycerol; BMI, body mass index.

glycemic load of the modern western diet, this contributes strongly to increased rates of obesity, unfavorable lipid profiles, insulin resistance, exacerbation of inflammation in the liver and kidneys, and increased cardiometabolic risk..$^{10,29,42,54,55}$

The critical role of $\mathrm{CB}_{1} \mathrm{R}$ in accumulation of energy reserves and BMI homeostasis is revealed in studies using $\mathrm{CB}_{1} \mathrm{R}$ antagonists, including rimonabant, as well as the peripherally restricted $\mathrm{CB}_{1} \mathrm{R}$ antagonists URB447 and AM6545. In laboratory and clinical trials, rimonabant was successful at reducing weight, but severe psychiatric side effects, including dizziness, anxiety, depression, and nausea, caused discontinuation of clinical trials. ${ }^{55,56}$

A therapeutic approach that acts both peripherally and centrally on the eCB system but does not cause se- vere psychiatric side effects is of great interest. Peripherally restricted $C_{1} R$ antagonists such as URB447 and AM6545 are showing promise, as peripheral eCB signaling via $\mathrm{CB}_{1} \mathrm{R}$ plays a key role in stimulation of hyperphagia and dietary fat intake in the context of the western diet. ${ }^{45,46}$ These trials highlight the importance of the eCB system as a target of interest in weight control strategies. ${ }^{43-46,51,55,56}$

The present study summarizes the data on Cannabis use, caloric intake, and BMI, establishing conclusively that Cannabis use is associated with reduced BMI and obesity rates, despite increased caloric intake. It then provides a theoretical, causative explanation for this paradox. This theory encompasses the causative role in obesity of dietary disruption of the $\mathrm{eCB}$ system by an elevated omega-6/omega-3 fatty acid ratio. Cannabis 
(or THC) results in downregulation of $\mathrm{CB}_{1} \mathrm{R}$, leading to reduced sensitivity to AEA and 2-AG, leading to significant health benefits in the context of this diet.

\section{Methods}

Data on the BMI of Cannabis users and nonusers, or studies reporting adjusted odds ratios (AORs) for Cannabis users being obese or overweight, were obtained from the literature. Studies addressing the health impact of Cannabis use were identified using database searches and citation lists. Studies addressing the impact of therapeutic Cannabis use by cancer or AIDS patients or other patients, as a means to increase appetite and caloric intake, were eliminated. Studies in which Cannabis was provided to nonusers over a several day period were rejected because short-term weight gain can be caused by water retention from increased sodium intake rather than accumulation of tissue mass. One study ${ }^{57}$ focused on imaging of $\mathrm{CB}_{1} \mathrm{R}$ was rejected due to low sample size ( $N=10$ users and $N=10$ nonusers).

The remaining data were compiled into a spreadsheet. Paired $t$-tests were used to compare BMI of users and nonusers and were followed by determination of effect size (Hedges $\mathrm{g}$ with bias correction)..$^{58}$ For rates of obesity, the mean and 95\% confidence intervals of AOR data, $\chi^{2}$ test for heterogeneity, and effect size determination using Hedges g were used to compare nonusers with users. When different usage rates were reported, data from the highest dosage group were used in the analysis. The mean across all usage groups, relative to nonusers, is also reported. Caloric intake data from short-term experimental studies were eliminated to ensure that subjects had reached a steady state.

\section{Results}

\section{BMI data}

Nine studies were included that reported BMI of users and nonusers and met selection criteria (Table 1), and an additional two studies were identified that reported lower BMI in Cannabis users, but did not provide numerical data. Of these studies, all reported lower values of BMI in Cannabis users, and only one of these did not reach statistical significance. A second study did not

Table 1. Published Values of Body Mass Index for Cannabis Users and Nonusers

\begin{tabular}{|c|c|c|c|c|c|}
\hline Reference & Nonuser & Usage pattern & Current user & $\begin{array}{l}\text { Current user, } \\
\text { highest dosage }\end{array}$ & $p$-Value or $95 \% \mathrm{Cl}$ \\
\hline $72^{a}$ & $28.6(335)$ & & 26.8 & $26.8(451)$ & $<0.001$ \\
\hline \multirow[t]{2}{*}{110} & $24.4(23,705)$ & (women) & 23 & $23(6504)$ & $<0.05$ \\
\hline & $25.4(14,324)$ & (men) & 24.3 & $24.3(7474)$ & $<0.05$ \\
\hline \multirow[t]{5}{*}{59} & $28.22(265)$ & & & & $<0.05$ (joint years) $<0.009$ \\
\hline & & $<5$ years & $26.8(552)$ & & (dependence) \\
\hline & & $5-10$ years & $27.1(42)$ & & \\
\hline & & $10-15$ years & $26.6(44)$ & & \\
\hline & & $15+$ years & $25.5(37)$ & $25.5(37)$ & \\
\hline \multirow[t]{3}{*}{60} & $28(6667)$ & & & & \\
\hline & & $1-4 \times /$ month & $24.8(557)$ & & $<0.001$ \\
\hline & & $>5 \times /$ month & $24.1(326)$ & $24.1(326)$ & $<0.001$ \\
\hline 86 & $29.1(2103)$ & & $27.2(579)$ & 27.2 (579) & $<0.0001$ \\
\hline \multirow[t]{4}{*}{70} & $28.9(2252)$ & & & & Not significantly different \\
\hline & & $<180$ days & $28.5(610)$ & & \\
\hline & & 180-1799 days & $28.7(601)$ & & \\
\hline & & $>1800$ days & $28.0(154)$ & $28(154)$ & \\
\hline \multirow[t]{4}{*}{$71^{b}$} & $26.6(9771)$ & & & & \\
\hline & & $1-4 \times /$ month & $25(541)$ & & \\
\hline & & $5-10 \times /$ month & $26.1(135)$ & & \\
\hline & & $11 \times+/$ month & 24.7 (176) & 24.7 (176) & $<0.0001$ \\
\hline 78 & $27(28)$ & & $24(30)$ & $24(30)$ & $<0.05$ \\
\hline 87 & $29.1(2861)$ & & $26.9(831)$ & $26.9(831)$ & $<0.0001$ \\
\hline 62 & Numerical data $n$ & led; user $\mathrm{BMI}<$ nor & & & Not provided \\
\hline 61 & Numerical data $n$ & led; lower BMI gro & tain more Can & ers, $R^{2}=0.96$ & $<0.02$ \\
\hline Mean & $27.5(N=60,0$ & & 26.0 & $25.5(N=18,272)$ & $<0.0005$ \\
\hline
\end{tabular}

Statistically significant differences between Cannabis users and nonusers are indicated with bold font.

${ }^{a}$ Adjusted for age (continuous), gender, small communities (yes/no), more than or equal to secondary school (yes/no), income level $(<\$ 20,000$, $>\$ 20,000$, do not know/refuse to answer), marital status (single, married/common law, separated/divorced/widowed), $3.5 \mathrm{~h} / \mathrm{week}$ of leisure physical activity (yes/no), smoking status (never/former/current smoker with 1-14 cig./day, 15-24 cig./day, 25 cig./day), ever drink alcohol (yes/no/do not know or refuse to answer), total energy intake (kcal/day).

${ }^{\mathrm{b}}$ Effect remained after adjustment for age, gender, education, cigarette smoking, and caloric intake $(p=0.003)$.

BMI, body mass index. 
report statistical analysis of the BMI data. Of those studies reporting significant negative correlations, two reported that longer duration of Cannabis use was associated with reduced BMI. ${ }^{59,60}$

Across all studies reporting BMI, the overall mean BMI of nonusers was $27.5 \mathrm{~kg} / \mathrm{m}^{2}$, while that of users (including data for all usage groups) was $26.0 \mathrm{~kg} / \mathrm{m}^{2}$ (Table 1). Limiting the analysis to the data from the highest dosage or duration of use reported in each study resulted in a mean BMI of users of $25.5 \mathrm{~kg} / \mathrm{m}^{2}$, a difference of $2 \mathrm{~kg} / \mathrm{m}^{2}$ that is significantly lower than the BMI of nonusers $(p<0.001$, paired $t$-test, $T=6.00$, Fig. 2 and Table 2). The effect size of Cannabis use on BMI is large (Hedges $\mathrm{g}$ with bias correction $=-1.16)^{58}$ and the magnitude of the difference in BMI of users and nonusers is of clinical significance. Thus, on average, nonusers in these studies are overweight, whereas Cannabis users are significantly leaner and are near the healthy BMI range $\left(18.5-25 \mathrm{~kg} / \mathrm{m}^{2}\right)$.

Further support for reduced BMI in Cannabis users comes from the study by Warren et al. ${ }^{61}$ Although Warren et al. ${ }^{61}$ did not report BMI values, they grouped obese patients by BMI. The percent of each group that consumed Cannabis was negatively and linearly related

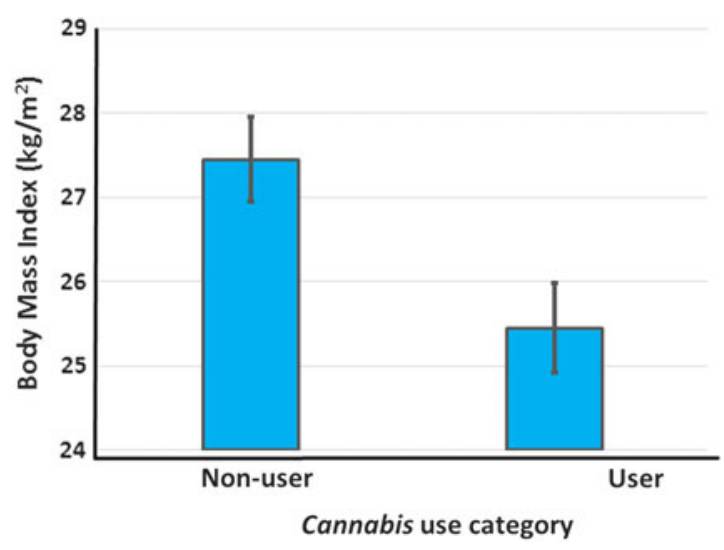

FIG. 2. A comparison of $B M I\left(\mathrm{~kg} / \mathrm{m}^{2}\right)$ of Cannabis users and nonusers. Data from current user, highest dosage presented in Table 1.

Available data show that nonusers are overweight on average, whereas the mean BMI of users is not different from the upper limit of the healthy weight range. Data are expressed as mean \pm SEM $(N=12$ data points from 11 studies, $p<0.001$; Hedges g statistic $=-1.16)$.
Table 2. Published Values for Adjusted Odds Ratios for Cannabis Users Being Obese and/or Overweight

\begin{tabular}{|c|c|c|c|c|}
\hline Reference & Usage category & OR users & $95 \% \mathrm{Cl}$ & $p$ \\
\hline \multicolumn{5}{|l|}{$111^{\mathrm{a}}$} \\
\hline \multirow{3}{*}{$\begin{array}{l}\text { NESARC, } \\
N=41,633\end{array}$} & $1+\times /$ year, $<1 \times /$ month & 0.70 & $0.63-1.05$ & $<0.001$ \\
\hline & $1 \times /$ month $-2 \times /$ week & 0.84 & $0.62-1.01$ & \\
\hline & Daily & 0.61 & $0.46-0.82$ & \\
\hline \multirow{3}{*}{$\begin{array}{l}\text { NCS-R, } \\
N=9103\end{array}$} & $1+\times /$ year,$<1 \times /$ month & 0.7 & $0.44-1.11$ & $<0.001$ \\
\hline & $1 \times /$ month $-2 \times /$ week & 0.84 & $0.54-1.31$ & \\
\hline & Daily & 0.73 & $0.43-1.23$ & \\
\hline $72^{b}$ & Past year & 0.56 & $0.37-0.84$ & $<0.05$ \\
\hline $63^{c}$ & $1 \times$ in last month & 0.8 & $0.5-1.2$ & \\
\hline \multirow[t]{2}{*}{$N=2566$} & Every few days & 0.5 & $0.3-0.8$ & $<0.01$ \\
\hline & Daily & 0.2 & $0.1-0.4$ & $<0.001$ \\
\hline $88^{d}$ & & 0.42 & $0.13-1.36$ & \\
\hline $65^{e}$ & High vs. low use & 0.2 & & $<0.01$ \\
\hline \multirow[t]{2}{*}{$N=5141$} & Sporadic vs. low use & 0.1 & & $<0.01$ \\
\hline & Increasing vs low & 1.6 & & $<0.05$ \\
\hline $112^{f}$ & Male, past year & & & \\
\hline \multirow[t]{5}{*}{$N=40,364$} & Overweight & 0.88 & $0.67-1.16$ & \\
\hline & Obese & 0.84 & $0.6-1.16$ & \\
\hline & Female, past year & & & \\
\hline & Overweight & 0.88 & $0.53-1.45$ & \\
\hline & Obese & 0.81 & $0.48-1.38$ & \\
\hline $\begin{array}{l}\text { Mean and } \\
\text { summary } \mathrm{Cl}\end{array}$ & & 0.68 & $0.53-0.84$ & $<0.05$ \\
\hline
\end{tabular}

Statistically significant differences between Cannabis users and nonusers are indicated with bold font. Only one data point shows AOR $>1$. Hedges g statistic $=-1.07$.

a Data from two databases, NESARC, National Epidemiologic Survey on Alcohol and Related Conditions (2001-2002); NCS-R, National Comorbidity Survey-Replication (2001-2003). Adjusted for sex, age, race/ethnicity, educational level, marital status, region, and tobacco smoking status. Prevalence of obesity significantly lower in Cannabis users in both data sets $(p<0.001)$

${ }^{\mathrm{b}}$ Age-standardized.

'Odds ratio for $\mathrm{BMI} \geq 25$. Adjusted for participant's gender and age, mother's age and education, participant's cigarette smoking, alcohol consumption, anxiety/depression and aggression/delinquency, participants BMI at 14 years.

${ }^{\mathrm{d}}$ Regular user, OR for abdominal obesity. Adjusted for age, gender, education, participation in at least moderate physical activity, weekly alcohol use, income to poverty ratio, having health insurance, marital status, other illicit drug use and having had rehabilitation.

${ }^{\mathrm{e}}$ Controlled for adolescent obesity status, gender, ethnicity, and average family income.

${ }^{f}$ Controlled for age, level of education, race/ethnicity, income, marital status, region of country, urban vs. rural residence, and lifetime and past year DSM-IV diagnoses of any mood disorder, any anxiety disorder, any personality disorder, any alcohol use disorder, and nicotine dependence.

AOR, adjusted odds ratio; DSM-IV, Diagnostic and Statistical Manual of Mental Disorders, 4th Edition.

to the BMI of the group $\left(R^{2}=0.96\right)$. Danielsson et al. ${ }^{62}$ also reported decreased rates of being overweight (BMI >24.9) in Cannabis users, but did not provide numerical data for BMI of the two groups. Thus, of 11 studies reporting data on the relationship between Cannabis use and BMI, 9 showed a significant negative relationship between Cannabis use and BMI while the remaining 2 either reported lower BMI values in Cannabis users than nonusers that did not 
reach statistical significance, or failed to provide statistical analyses (Table 1).

Of course, decreased BMI in Cannabis users could result from activities correlated with Cannabis use, rather than Cannabis use itself. Two of the BMI studies adjusted for potential confounders, and significant differences remained following adjustment (Table 1). Six studies were identified that reported AORs of Cannabis users being obese or overweight (Table 2).

Hayatbakhsh et al. ${ }^{63}$ followed a cohort of patients from birth until age 21 and found that subjects who used Cannabis showed a strongly reduced incidence of being overweight or obese relative to nonusers. A fully adjusted model that included BMI at age 14 yielded an AOR of 0.2 for daily users being overweight $(95 \% \mathrm{CI}=0.1-0.4)$. BMI was inversely correlated with the frequency of Cannabis use, lending support for causation. $^{63}$

Waterreus et al. ${ }^{64}$ found that a significantly lower percentage of users than nonusers were obese $(53.7 \%$ of nonusers, $36.7 \%$ of occasional users, and $28.7 \%$ of frequent users were obese; $p<0.001$ ).

Huang et al. ${ }^{65}$ studied three categories of adolescent Cannabis users; high users, sporadic users, and increasing users. Sporadic and high usage groups showed far lower obesity rates than low users (AOR for sporadic use $=0.2$ and for high use $=0.1$ ). In contrast, the subjects on the increasing usage trajectory showed increased obesity rates relative to low users $(\mathrm{AOR}=1.6)$. This was the only report identified in the literature of an AOR for obesity $>1$.

The mean AOR across data points from these studies was 0.68 . The effect size was large (Hedges' g with bias correction $=-1.074, N_{\text {cannabis }}=18$, and $\left.N_{\text {control }}=6\right),{ }^{58}$ and the mean odds ratio of users across all studies and usage groups (mean $\mathrm{OR}=0.68$ ) suggests obesity rates are reduced enough in users to provide significant health benefits. Several tests were used to evaluate heterogeneity of the AOR data. The $95 \%$ confidence interval of the AOR data of users did not include 1 (95\% CI $=0.53-0.84)$. The Wilcoxon rank-sum test using data from the highest usage rates within each study or group resulted in a significant impact of Cannabis use on AOR $\left(0.0025<p<0.005 ; N_{1}=N_{2}=9\right.$, $U=9,72)$. The $\chi^{2}$ test using data from all user groups failed to reject the null hypothesis, however $\left(\chi^{2}=3.78,0.1<p<0.05\right)$.

A recent review cited Mittleman ${ }^{66}$ as reporting increased obesity rates in Cannabis users, ${ }^{34}$ but this appears to be a misinterpretation of the data presented in that study. Mittleman et al. ${ }^{66}$ showed that, of patients who had suffered a myocardial infarction (MI), those who used Cannabis were more likely to be obese. This is quite different from finding that Cannabis users were more likely to be obese. These data could be interpreted instead as evidence for protection of nonobese Cannabis users from MI. These data were therefore not included in the analysis.

Overall, 17 studies have presented data from 19 data sets on the relationship between Cannabis use and body mass or rates of obesity. These studies provided a total of 36 individual data points for BMI or AOR, and 35 of these show BMI or obesity values for Cannabis users that are less than values for nonusers. Both the BMI data and the AOR data show lower BMI or rates of overweight or obesity in Cannabis users (BMI: paired $t$-test $p<0.001$; AOR 95\% CI=0.53-0.84) (Tables 1 and 2). Both data sets show strong effect sizes (Hedges g: $\mathrm{BMI}=-1.16$ and obesity $\mathrm{AOR}=-1.07) .{ }^{58}$

Further evidence comes from the recent observation that legalization of medical Cannabis at the state level is associated with a rapid decrease in statewide obesity rates, ${ }^{67}$ and that obese rats exposed to Cannabis extract show reduced rates of weight gain. ${ }^{68}$ Indeed, the inverse relationship between obesity and Cannabis use in humans led Le Foll et al. ${ }^{69}$ to propose Cannabis as a possible therapeutic option for weight loss, and evidence accumulated since then has only strengthened the association.

\section{Caloric intake data}

Interestingly, frequent Cannabis users appear to have increased caloric intake relative to nonusers, despite lower BMI.

Rodondi et al. ${ }^{70}$ found that users who had consumed Cannabis for more than 1800 days over 15 years consumed on average 619 more calories/day than nonusers, yet showed no difference in BMI (Table 1).

Smit and Crespo $^{71}$ reported lower BMI in users $(24.7 \pm 0.3)$ than nonusers $(26.6 \pm 0.1)$, despite users consuming 564 additional calories relative to nonusers $(p<0.0001)$.

Ngueta et al. ${ }^{72}$ also observed higher values for caloric intake in Cannabis users relative to nonusers; although this was not statistically significant $(2375 \mathrm{kcal} /$ day vs. $2210 \mathrm{kcal} /$ day; $p=0.07)$. Despite this, the users had lower BMI $(p<0.001)$.

Foltin et al. ${ }^{73}$ found Cannabis users to have a substantial increase $(1095 \mathrm{kcal} /$ day $)$ in daily caloric intake, although this was a short-term experimental study 
rather than a comparison between free-range Cannabis users and nonusers.

Across these studies, on average, Cannabis users consumed an additional $834 \mathrm{kcal} /$ day relative to nonusers. As BMI of Cannabis users is lower than nonusers, this suggests that Cannabis users must have increased metabolic rates.

\section{Previous explanations proposed for lower $\mathrm{BMI}$ in Cannabis users}

Any theory explaining mechanistically how Cannabis use causes reduced BMI must consider the paradoxical increase in caloric intake of users. To date, such a theory is lacking and the interactions between Cannabis use and obesity are not well understood. ${ }^{34}$

Proposed explanations for reduced BMI in Cannabis users include substitution of Cannabis for food in brain reward pathways. ${ }^{61}$ Pagotto et al. ${ }^{74}$ suggested that the sedative effects of high doses of Cannabis could reduce food consumption, but Rajavashisth et al. ${ }^{60}$ observed detectable effects on BMI at usage rates of four times or less per month (25\% of nonusers were obese, whereas $16 \%$ of people who used Cannabis one to four times/month were obese, $p<0.001)$. Sabia et al. ${ }^{67}$ suggested that reduced alcohol use by younger users, and increased physical activity of older users upon initiating medical marijuana use, may be responsible for the observed decrease in BMI.

While all of these factors may contribute, reduced BMI in conjunction with increased caloric intake strongly suggests that the mechanisms causing the observed decreases in BMI or obesity rates of Cannabis users must include differences in metabolism, not changes in caloric intake or activity-related energy expenditures alone. These explanations obviously do not account for increased caloric intake in Cannabis users. Le Foll et al. ${ }^{69}$ suggested that $\Delta^{9}$-tetrahydrocannabinol (THC) may act as a functional antagonist in high $\mathrm{eCB}$ tone, as occurs in obesity, reducing BMI in Cannabis users. ${ }^{69}$ This is essentially what we are proposing, but does not address the mechanism involved.

\section{Theoretical explanation for the decreased}

BMI of Cannabis users

There are currently no proposed mechanisms for reduced BMI in Cannabis users that account for their

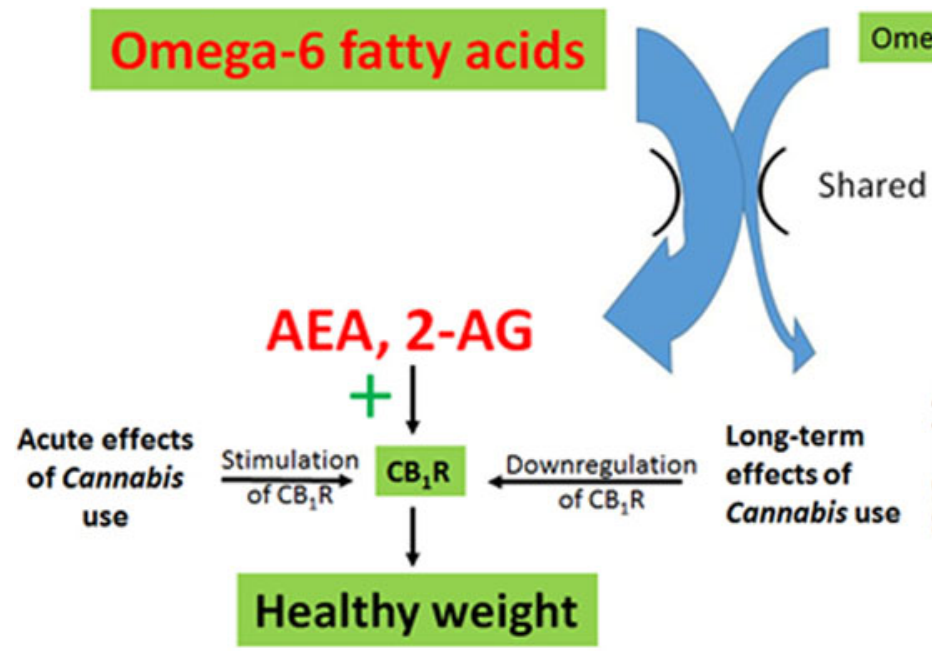

Omega-3 fatty acids

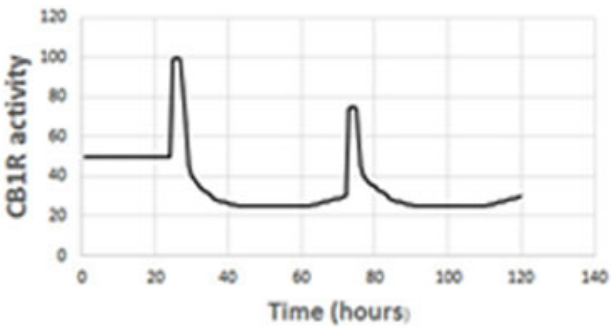

FIG. 3. The impact of Cannabis use on the endocannabinoid system of people consuming a diet characterized by an elevated omega-6/omega-3 ratio. Acute effects of Cannabis and/or THC consumption include hypothermia and hyperphagia, leading to increased energy intake and storage. However, Cannabis use also causes long-term downregulation of $C B_{1} R$, leading to decreased $C B_{1} R$ activity, as shown in the insert on the lower right, in which each spike follows acute Cannabis ingestion, while the overall activity level remains depressed. Decreased $C B_{1} R$ activity results in a decrease in energy assimilation and an increase in metabolic rates, resulting in a decline in body mass despite stimulation of $C_{1} B_{1}$ during acute exposure. THC, $\Delta^{9}$-tetrahydrocannabinol. 
increased caloric intake. The central role of $\mathrm{CB}_{1} \mathrm{R}$ in appetite, energy intake, energy conservation, and dietinduced obesity, and the hyperphagia and hypothermia resulting from acute stimulation of $\mathrm{CB}_{1} \mathrm{R}$ by $\mathrm{THC}$, makes $\mathrm{CB}_{1} \mathrm{R}$ a prime suspect for a causative role in the effects of Cannabis use on BMI. ${ }^{22-24,27-32,41-46,74,75}$

A novel theory for the impact of Cannabis use on $\mathrm{BMI}$ involving changes in $\mathrm{CB}_{1} \mathrm{R}$ expression is proposed here (Fig. 3). This multipart theory includes the following components:

1. A diet characterized by an elevated ratio of omega-6/omega-3 fatty acids, typical of processed foods high in grains and soybean oil, and animals reared on these foods, results in elevated levels of the eCB signals AEA and 2-AG.

The evidence is well established. ${ }^{19,22,23,25,28,49}$

2. Elevated AEA and 2-AG act to overstimulate the eCB receptor $\mathrm{CB}_{1} \mathrm{R}$, resulting in increased appetite and palatability of food, increased rates of energy uptake and storage, and decreased resting metabolic rates. These result in dysregulation of glucose and lipid metabolism, metabolic syndrome, and obesity.

The evidence is well established and is summarized in multiple recent reviews, for example, see Refs. ${ }^{19,22,23,27-29}$

3. Decreased $C_{1} R$ activity reduces obesity and metabolic disruption. Strong evidence in support of this statement is provided in laboratory experiments and clinical trials using $\mathrm{CB}_{1} \mathrm{R}$ antagonists, including rimonabant, AM6545, and URB447.

Rimonabant caused weight loss, improved lipid profiles, improved glucose sensitivity, and reduced atherosclerosis in animals and human subjects. ${ }^{55,56,76}$ Unfortunately, it also caused severe psychiatric side effects in clinical trials, including depressive disorders, dizziness, nausea, and anxiety, and trials were therefore terminated. ${ }^{55,56,76}$ The peripherally restricted $\mathrm{CB}_{1} \mathrm{R}$ antagonists, AM6545 and URB447, decreased sham feeding of fatty foods and hyperphagia in rats, reducing caloric intake. ${ }^{45,46}$

4. Cannabis use causes downregulation of $\mathrm{CB}_{1} \mathrm{R}$, reducing the impact of enhanced AEA and 2-AG production arising from an elevated dietary omega6/omega-3 ratio.

Multiple studies show that $\mathrm{CB}_{1} \mathrm{R}$ is downregulated during Cannabis tolerance, and the receptor remains downregulated for about 3-4 weeks after cessation of use. .777-80 $^{5}$

\section{Observations supporting this theory}

There is abundant evidence that rates of obesity and metabolic syndrome are increasing with changes in diet. $^{1-4,6,13,14,16,33,81}$

There is abundant evidence that these dietary changes include a shift to a high omega-6/omega-3 ratio. ${ }^{13-19,22,23}$

There is abundant evidence that an elevated omega6/omega- 3 ratio increases eCB tone by increasing AEA and 2-AG levels, overstimulating $\mathrm{CB}_{1} \mathrm{R}^{15,18,19,22-30,55,82}$

There is abundant evidence that overstimulation of $C_{1} R$ increases adiposity and leads to metabolic syndrome, contributing to chronic diseases. ${ }^{10,18,19,22,23,25,27-32,41-46,54,55,82}$

There is abundant evidence that reduced $\mathrm{CB}_{1} \mathrm{R}$ activity results in weight loss. eCBs are strongly involved in energy expenditures, increasing caloric intake, and reducing whole-body energy metabolism. ${ }^{24,28,31,32,41-46,48,50,52,55}$ The $\mathrm{CB}_{1} \mathrm{R}$ antagonist rimonabant increases $\mathrm{O}_{2}$ consumption and resting energy expenditures in both rats and in humans. In rats, it increases $\mathrm{O}_{2}$ consumption by $18 \%$ at a dosage of $3 \mathrm{mg} /$ $\mathrm{kg}$ and $49 \%$ at $10 \mathrm{mg} / \mathrm{kg}$ after $3 \mathrm{~h}$ of exposure. In humans, it increases resting energy expenditures of overweight or obese subjects and leads to weight loss. ${ }^{55,56}$ Similarly, the peripherally restricted $\mathrm{CB}_{1} \mathrm{R}$ antagonists URB447 and AM6545 reduce energy intake. URB447 reduced rates of fat ingestion in sham-feeding rats, while AM6545 attenuated diet-induced hyperphagia. ${ }^{43,44}$

There is abundant evidence that exposure to Cannabis and/or THC results in downregulation of $\mathrm{CB}_{1} \mathrm{R}$. Regular Cannabis use is associated with desensitization and downregulation of $\mathrm{CB}_{1} \mathrm{R}$, and $\mathrm{CB}_{1} \mathrm{R}$ levels remain depressed for 3-4 weeks following cessation of use. ${ }^{57,77-80}$ Because $\mathrm{CB}_{1} \mathrm{R}$ plays a major role in assimilation, storage, and conservation of energy, this downregulation results in decreased eCB tone. According to the theory put forth in this article, acute exposure results in the "munchies," stimulating appetite and energy consumption and causes hypothermia as metabolic rates decrease. However, rapid downregulation of $\mathrm{CB}_{1} \mathrm{R}$ following consumption leads to long-term effects that more than offset the short-term increase in energy stores that follow acute exposures.

The current meta-analysis provides strong evidence that Cannabis use, and/or exposure to THC, results in reduced BMI (Tables 1 and 2 and Fig. 2). 
Predictions arising from theory

Prediction 1: Cannabis users lose additional weight during abstinence. BMI is reduced in Cannabis users, and should decrease even more when users stop using Cannabis, because $\mathrm{CB}_{1} \mathrm{R}$ remains downregulated for several weeks following chronic Cannabis consumption. ${ }^{57,77-80}$ Recently abstinent users would show reduced appetite and increased metabolic rates during this time. However, they will no longer experience short-term stimulation of appetite, energy intake and storage, and reduced metabolic rates during each episode of acute Cannabis consumption. Therefore, weight loss will increase as energy intake and storage remain depressed, and metabolism stimulated, until $\mathrm{CB}_{1} \mathrm{R}$ returns to pre-Cannabis use levels.

This prediction is supported, as weight loss during withdrawal from Cannabis is one of the seven symptoms of Cannabis withdrawal listed in DSM-V. ${ }^{83,84}$

Prediction 2: moderate Cannabis use reduces the incidence of disorders associated with obesity and metabolic syndrome. Because Cannabis use is associated with reduced rates of obesity, it should also reduce rates of obesity-related diseases in users. There is some evidence for this, but results are inconsistent.

Multiple studies, including several using the National Health and Nutrition Examination Survey (NHANES) database, have reported in Cannabis users reduced rates of DM, insulin insensitivity, or metabolic syndrome in fully adjusted models, including age. ${ }^{60,64,72,85-87}$ Yankey et al. ${ }^{88}$ also reported decreased DM rates (AOR 0.42) that did not reach statistical significance $(95 \% \mathrm{CI}=0.13-$ 1.36). In contrast, analysis of data from the CARDIA data set failed to detect this relationship. ${ }^{89}$ Danielsson et al. ${ }^{62}$ found decreased rates of DM in Cannabis users in a dataset of Swedish conscripts (OR 0.74), but unlike the studies from the NHANES data set, this effect was no longer significant after adjustment for age (AOR 0.74 before adjustment, 0.94 after adjustment).

Cannabinoids have potent anticancer properties, ${ }^{15,90}$ and a recent review concluded that Cannabis users may have lower rates of cancer than nonusers. ${ }^{91}$ Multiple laboratory studies have shown that THC slows or reverses the progression of Alzheimer's disease, although clinical trials are lacking. ${ }^{92-96}$ In contrast, evidence available to date does not support reduced rates of cardiovascular disease in Cannabis users, ${ }^{97}$ although more studies are clearly warranted on this topic.
Prediction 3: the occurrence and magnitude of metabolic benefits from Cannabis use depend on the dietary omega-6/omega-3 ratio. The impact of diet on the $\mathrm{eCB}$ system is predicted to differ among populations because different populations have different diets, consuming different proportions of green vegetables, industrially produced animals, oceanic fishes, and processed foods.

According to the theory established in the current article, populations with diets characterized by a high omega-6/omega-3 ratio will see significantly larger health improvements from Cannabis use than those eating diets with more moderate ratios of omega-6/ omega-3 FAs. This may explain some of the inconsistencies in the data on the metabolic impact of Cannabis use; for example, Cannabis use by Swedish populations $^{62,98}$ may not have the same health impacts as Cannabis use by Americans due to the different dietary backgrounds and obesity rates of these populations.

Cannabis use in the United States appears to provide significant public health benefits due to partial or complete reversal of the metabolic dysregulation caused by the strongly elevated omega-6/omega-3 ratio of the American diet.

Prediction 4: Cannabis use and omega-3 supplements have similar impacts on health. Both omega-3 FAs and Cannabis reduce eCB tone, through distinct mechanisms. Omega-3 FAs compete with omega-6 FAs for the enzymes synthesizing AEA and 2-AG from omega- 6 FAs, and omega-3 supplements thereby reduce the synthesis of AEA and 2-AG and reduce stimulation of $\mathrm{CB}_{1} \mathrm{R}^{13,21,22,25,49}$

Cannabis use causes downregulation of $\mathrm{CB}_{1} \mathrm{R}^{57,77-80}$ reducing the sensitivity to elevated AEA and 2-AG. Thus, the theory predicts that omega- 3 FA supplements and Cannabis use should have similar positive health impacts in the context of metabolic dysregulation from a diet with an elevated omega-6/omega-3 ratio. However, it is likely that the overlap is not complete as the precursor of AEA and 2-AG, arachidonic acid, ${ }^{22}$ also gives rise to proinflammatory leukotrienes and prostaglandins, ${ }^{99}$ an effect that might not be impacted by decreased $\mathrm{CB}_{1} \mathrm{R}$ tone.

Prediction 5: the combination of omega-3 supplements and Cannabis or cannabinoids could be a particularly potent treatment for obesity, metabolic syndrome, cancer, and so on. Reducing AEA and 2-AG synthesis with omega-3 supplements, and at the same time reducing $\mathrm{CB}_{1} \mathrm{R}$ density with Cannabis 


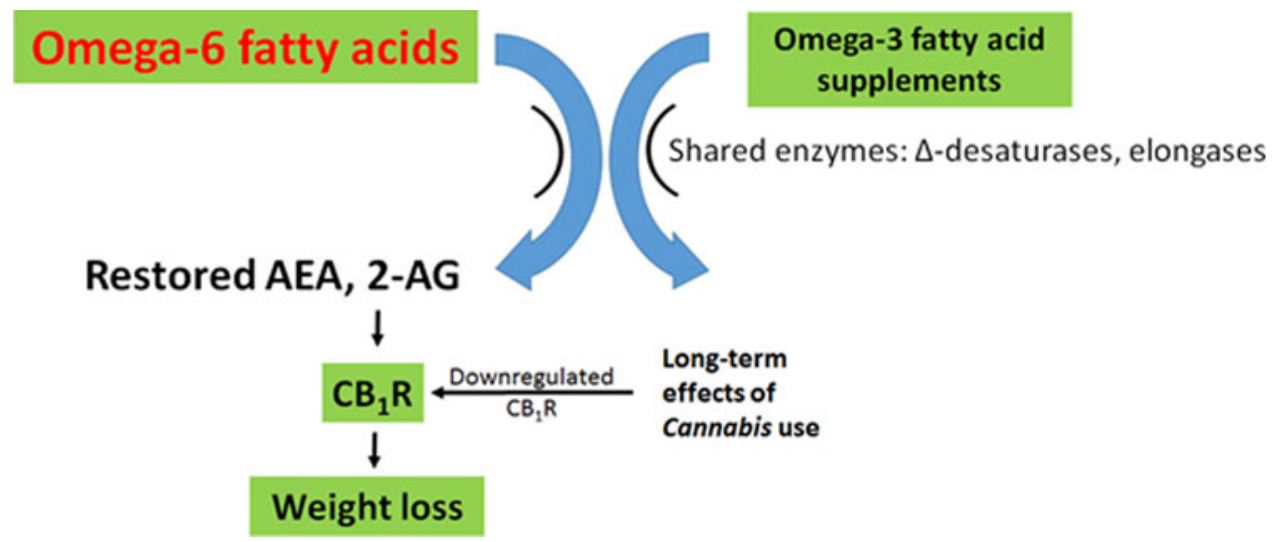

FIG. 4. Proposed weight loss therapy based on theory. Daily omega-3 fatty acid supplements (especially with decreased dietary omega- 6 fatty acids) will reduce levels of $A E A$ and $2-A G$, reducing stimulation of $C B_{1} R$, while weekly Cannabis use will cause downregulation of $C B_{1} R$. Thus, this approach will act to both reduce levels of the endocannabinoid signals and reduce the sensitivity of target cells to those signals. The net effect is predicted to be a more potent weight loss strategy than diet alone.

use, should reduce BMI and cardiometabolic risk factors more than either option alone (Fig. 4). Note that, because $\mathrm{CB}_{1} \mathrm{R}$ remains downregulated for some time following use, weekly Cannabis use may be sufficient to observe significant weight loss and metabolic benefits.

\section{Conclusions/Summary}

Obesity and elevated BMI are strongly associated with disease states, and there are significant financial and public health incentives to develop effective interventions to help people achieve a healthy body mass. Pharmacological weight loss therapy is recommended when $\mathrm{BMI}$ is $\geq 27$ in the presence of obesity-related risk factors and $>30$ in the absence of such risk factors. ${ }^{53}$

The development of pharmacological weight loss methods has been problematic, Rimonabant, a $\mathrm{CB}_{1} \mathrm{R}$ antagonist, showed promise in laboratory studies, but clinical trials were discontinued due to serious psychiatric side effects, ${ }^{53,54}$ although ongoing studies suggest that peripherally restricted $\mathrm{CB}_{1} \mathrm{R}$ antagonists may provide therapeutic benefits in obesity without such psychiatric side effects. ${ }^{43-46}$

Surgical methods such as the lap band or bariatric surgeries are frequently used when dietary or pharmaceutical interventions do not work, and any surgical procedure entails risk and recovery. Surgical procedures are also expensive. Therefore, relatively safe and inexpensive methods to reduce obesity and prevent or reduce some of the most deadly and costly chronic diseases characterizing western societies merit serious consideration.
For many patients, Cannabis may be a better option for weight loss than surgery or pharmaceuticals. However, patients with preexisting cardiovascular conditions or prior MIs should avoid cannabinoids or use them with caution. ${ }^{66,91,100}$

A number of states and the federal government have legalized Cannabis products containing cannabidiol, but continue to ban legal access to products containing THC. Evidence available at this time suggests that it is ingestion of THC that is responsible for downregulation of $\mathrm{CB}_{1} \mathrm{R}$, and therefore, for reduced obesity rates of Cannabis users. Our theory suggests that the psychoactive effects of $\mathrm{CB}_{1} \mathrm{R}$ stimulation with THC may be a necessary accompaniment to Cannabis-induced weight loss, because downregulation of $\mathrm{CB}_{1} \mathrm{R}$ is required for reduced $\mathrm{BMI}$, and it is not yet clear whether microdosing will cause downregulation. However, weekly or biweekly Cannabis use may be sufficient as significant decreases in BMI are observed at weekly usage rates. ${ }^{60}$

Medical marijuana use is increasing, leading to decreased use of multiple classes of pharmaceuticals. Patients cite improved symptom management, fewer adverse side effects, and milder withdrawal symptoms as reasons for switching from pharmaceuticals to medical Cannabis. ${ }^{101-108}$ Once patients become aware that the side effects of medical Cannabis may include weight loss and reduced risk of obesity-associated medical conditions, this shift toward medical Cannabis is likely to accelerate. Available data suggest that this will save many lives, not only from reduced rates of 
obesity-related chronic illnesses but also from reduced deaths from pharmaceutical overdose. ${ }^{91,105,109}$

This study provides a theoretical platform to inform future studies on the correlations between Cannabis use and cardiometabolic risk factors. This theory may explain inconsistencies among studies on the impact of Cannabis use on metabolic dysregulation, as different populations have different diets. For example, epidemiological studies of the impact of Cannabis use by cohorts of Swedish conscripts may reveal different results than epidemiological studies in the United States, due to different levels of obesity in the two countries. Cerdá et al. ${ }^{98}$ found that early, heavy Cannabis use among Swedish conscripts is associated with increased mortality later in life. In contrast, Clark ${ }^{91}$ concluded that Cannabis use is associated with a substantial decrease in the premature death rate in the United States, as it is associated with reduced rates of cancer, DM, pharmaceutical use, deaths from brain trauma, and may slow the progression of Alzheimer's and other neurodegenerative diseases.

The strong evidence for interactions between the dietary omega-6/omega-3 ratio, obesity, and Cannabis use suggests that the balance between positive and negative health impacts of Cannabis use will differ in Swedish and United States populations. Evidence suggests that, in the United States, many people may actually achieve net health benefits from moderate Cannabis use, due to reduced risk of obesity and associated diseases.

\section{Acknowledgments}

The authors thank Nicholas Cwidak, Jared Shepherd, Sam Ratkiewicz, Adriana Celis, Allie Hutt, Sarah Woods, Rebecca Shembarger, Cyndi Sofhauser, and Murlidharan Nair for helpful discussions.

\section{Author Disclosure Statement}

No competing financial interests exist.

\section{References}

1. Murray CJ, Abraham J, Ali MK, et al. The state of US health, 1990-2010: burden of diseases, injuries, and risk factors. JAMA. 2013;310:591-608.

2. Cordain L, Eaton SB, Sebastian A, et al. Origins and evolution of the Western diet: health implications for the 21st century. Am J Clin Nutr. 2005;81:341-354.

3. Esser N, Legrand-Poels S, Piette J, et al. Inflammation as a link between obesity, metabolic syndrome and type 2 diabetes. Diabetes Res Clin Pract. 2014;105:141-150.

4. Giugliano D, Ceriello A, Esposito K. The effects of diet on inflammation: emphasis on the metabolic syndrome. J Am Coll Cardiol. 2006;48: 677-685.

5. Manzel A, Muller DN, Hafler DA, et al. Role of "Western diet" in inflammatory autoimmune diseases. Curr Allergy Asthm. 2014;14:404.
6. Bosma-den Boer MM, van Wetten M-L, Pruimboom L. Chronic inflammatory diseases are stimulated by current lifestyle: how diet, stress levels and medication prevent our body from recovering. Nutr Metab. 2012;9:32.

7. Lontchi-Yimagou E, Sobngwi E, Matsha TE, et al. Diabetes mellitus and inflammation. Curr Diab Rep. 2013;13:435-444.

8. Farooqui AA, Farooqui T, Panza F, et al. Metabolic syndrome as a risk factor for neurological disorders. Cell Mol Life Sci. 2012;69: 741-762.

9. Kaur J. A comprehensive review on metabolic syndrome. Cardiol Res Pract. 2014;2014:943162.

10. Khan SA, Ali A, Khan SA, et al. Unraveling the complex relationship triad between lipids, obesity, and inflammation. Mediators Inflamm. 2014; 2014:502749.

11. Jourdan T, Godlewski G, Kunos G. Endocannabinoid regulation of $\beta$-cell functions: implications for glycaemic control and diabetes. Diabetes Obes Metab. 2016;18:549-557.

12. Galland L. Diet and inflammation. Nutr Clin Pract. 2010;25:634-640.

13. Wall R, Ross RP, Fitzgerald GF, et al. Fatty acids from fish: the antiinflammatory potential of long-chain omega-3 fatty acids. Nutr Rev. 2010;68:280-289.

14. Aguilar $M$, Bhuket $T$, Torres $S$, et al. Prevalence of the metabolic syndrome in the United States, 2003-2012. JAMA. 2015;313:19731974.

15. Brown I, Cascio MG, Rotondo D, et al. Cannabinoids and omega-3/6 endocannabinoids as cell death and anticancer modulators. Prog Lipid Res. 2013;52:80-109.

16. Blasbalg $T L$, Hibbeln JR, Ramsden $C E$, et al. Changes in consumption of omega-3 and omega- 6 fatty acids in the United States during the 20th century. Am J Clin Nutr. 2011;93:950-962.

17. Jing $\mathrm{K}, \mathrm{Wu} \mathrm{T}$, Lim K. Omega-3 polyunsaturated fatty acids and cancer. Anticancer Agents Med Chem. 2013;13:1162-1177.

18. Simopoulos AP. The importance of the ratio of omega-6/omega- 3 essential fatty acids. Biomed Pharmacother. 2002;56:365-379.

19. Simopoulos AP. An increase in the omega-6/omega-3 fatty acid ratio increases the risk for obesity. Nutrients. 2016;8:128.

20. Kelly OJ, Gilman JC, Kim Y, et al. Long-chain polyunsaturated fatty acids may mutually benefit both obesity and osteoporosis. Nutr Res. 2013;33: 521-533.

21. Kim J, Li Y, Watkins BA. Fat to treat fat: emerging relationship between dietary PUFA, endocannabinoids, and obesity. Prostaglandins Other Lipid Mediat. 2013;104-105:32-41.

22. Freitas HR, Isaac AR, Malcher-Lopes $R$, et al. Polyunsaturated fatty acids and endocannabinoids in health and disease. Nutr Neurosci. 2018, 21:695-714.

23. Mazier W, Saucisse N, Gatta-Cherifi B, et al. The endocannabinoid system: pivotal orchestrator of obesity and metabolic disease. Trends Endocrinol Metab. 2015;26:524-537.

24. Matias I, Di Marzo V. Endocannabinoids and the control of energy balance. Trends Endocrinol Metab. 2007;18:27-37.

25. Bisogno T, Maccarrone $M$. Endocannabinoid signaling and its regulation by nutrients. Biofactors. 2014;40:373-380.

26. De Petrocellis L, Di Marzo V. An introduction to the endocannabinoid system: from the early to the latest concepts. Best Pract Res Clin Endocrinol Metab. 2009;23:1-15.

27. Matias I, Petrosino S, Racioppi A, et al. Dysregulation of peripheral endocannabinoid levels in hyperglycemia and obesity: effect of high fat diets. Mol Cell Endocrinol. 2008;286:S66-S78.

28. DiPatrizio NV, Piomelli D. The thrifty lipids: endocannabinoids and the neural control of energy conservation. Trends Neurosci. 2012;35: 403-411.

29. Engeli S. Dysregulation of the endocannabinoid system in obesity. J Neuroendocrinol. 2008;20:110-115.

30. Engeli S, Böhnke J, Feldpausch M, et al. Activation of the peripheral endocannabinoid system in human obesity. Diabetes. 2005;54: 2838-2843.

31. Cota D, Marsicano G, Lutz B, et al. Endogenous cannabinoid system as a modulator of food intake. Int J Obes Relat Metab Disord. 2003;27: 289-301.

32. Cota D, Marsicano G, Tschöp $M$, et al. The endogenous cannabinoid system affects energy balance via central orexigenic drive and peripheral lipogenesis. J Clin Invest. 2003;112:423-431. 
33. O'Neill S, O'Driscoll L. Metabolic syndrome: a closer look the growing epidemic and its associated pathologies. Obes Rev. 2015;16:1-12.

34. Vidot DC, Prado G, Hlaing WM, et al. Emerging issues for our nation's health: the intersection of marijuana use and cardiometabolic disease risk. J Addict Dis. 2014;33:1-8.

35. Haan MN. Therapy Insight: type 2 diabetes mellitus and the risk of late-onset Alzheimer's disease. Nat Clin Pract Neurol. 2006;2: $159-166$.

36. Bisogno T, Di Marzo V. The role of the endocannabinoid system in Alzheimer's disease: facts and hypotheses. Curr Pharm Des. 2008;14: 2299-3305.

37. Di Marzo V, Melck D, Bisogno T, et al. Endocannabinoids: endogenous cannabinoid receptor ligands with neuromodulatory action. Trends Neurosci. 1998;21:521-528.

38. Bab I, Ofek O, Tam J, et al. Endocannabinoids and the regulation of bone metabolism. J Neuroendocrinol. 2008;20:69-74.

39. Bab I, Zimmer A, Melamed E. Cannabinoids and the skeleton: from marijuana to reversal of bone loss. Ann Med. 2009;41:560-567.

40. Purohit V, Rapaka R, Shurtleff D. Role of cannabinoids in the development of fatty liver (steatosis). AAPS J. 2010;12:233-237.

41. Cardinal P, Bellocchio $L$, Clark $S$, et al. Hypothalamic CB1 cannabinoid receptors regulate energy balance in mice. Endocrinology. 2012;153: 4136-4143.

42. Alvheim AR, Torstensen BE, Lin $\mathrm{YH}$, et al. Dietary linoleic acid elevates the endocannabinoids 2-AG and anandamide and promotes weight gain in mice fed a low fat diet. Lipids. 2014;49:59-69.

43. Heinitz $S$, Basolo $A$, Piaggi $P$, et al. Peripheral endocannabinoids associated with energy expenditures in Native Americans of Southwestern heritage. J Clin Endocrinol Metab. 2018;103:1077-1087.

44. Heinitz S, Basolo A, Piomelli D, et al. Endocannabinoid anandamide mediates the effect of skeletal muscle sphingomyelins on human energy expenditure. J Clin Endocrinol Metab. 2018;103:3757-3766.

45. DiPatrizio NV, Astarita G, Schwartz G, et al. Endocannabinoid signal in the gut controls dietary fat intake. Proc Natl Acad Sci U S A. 2011;108: 12904-12908.

46. Argueta DA, DiPatrizio NV. Peripheral endocannabinoid signaling controls hyperphagia in western diet-induced obesity. Physiol Behav. 2017 171:32-39.

47. Bigford GE, Del Rossi G. Supplemental substances derived from foods as adjunctive therapeutic agents for treatment of neurodegenerative diseases and disorders. Adv Nutr. 2014;5:394-403.

48. Rhee JJ, Kim E, Buring JE, et al. Fish consumption, omega-3 fatty acids, and risk of cardiovascular disease. Am J Prev Med. 2017:52:10-19.

49. Berge K, Piscitelli F, Hoem N, et al. Chronic treatment with krill powder reduces plasma triglyceride and anandamide levels in mildly obese men. Lipids Health Dis. 2013;12:78.

50. Hu FB, Bronner L, Willett WC, et al. Fish and omega-3 fatty acid intake and risk of coronary heart disease in women. JAMA. 2002;287: 1815-1821.

51. Farrimond JA, Mercier MS, Whalley BJ, et al. Cannabis sativa and the endogenous cannabinoid system: therapeutic potential for appetite regulation. Phytother Res. 2011;25:170-188.

52. Quarta C, Bellocchio L, Mancini G, et al. CB 1 signaling in forebrain and sympathetic neurons is a key determinant of endocannabinoid actions on energy balance. Cell Metab. 2010;11:273-285.

53. Cluny NL, Reimer RA, Sharkey KA. Cannabinoid signalling regulates inflammation and energy balance: the importance of the brain-gut axis. Brain Behav Immun. 2012;26:691-698.

54. Gertsch J. Cannabimimetic phytochemicals in the diet-an evolutionary link to food selection and metabolic stress adaptation? Br J Pharmacol. 2017; 174:1464-1483.

55. Ginsberg HN, Woods SC. The endocannabinoid system: potential for reducing cardiometabolic risk. Obesity. 2009;17:1821-1829.

56. Van Gaal LF, Rissanen AM, Scheen AJ, et al. Effects of the cannabinoid-1 receptor blocker rimonabant on weight reduction and cardiovascular risk factors in overweight patients: 1-year experience from the RIOEurope study. Lancet. 2005;365:1389-1397.

57. Ceccarini J, Kuepper R, Kemels D, et al. [18F] MK-9470 PET measurement of cannabinoid CB1 receptor availability in chronic cannabis users. Addict Biol. 2015;20:357-367.

58. Durlak JA. How to select, calculate, and interpret effect sizes. J Pediatr Psychol. 2009;34:917-928.
59. Meier MH, Caspi A, Cerdá M, et al. Associations between Cannabis use and physical health problems in early midlife a longitudinal comparison of persistent Cannabis vs tobacco users. JAMA Psychiatry. 2016;73: 731-740.

60. Rajavashisth TB, Shaheen M, Norris KC, et al. Decreased prevalence of diabetes in marijuana users: cross-sectional data from the National Health and Nutrition Examination Survey (NHANES) III. BMJ Open. 2012; 2:e000494.

61. Warren M, Frost-Pineda K, Gold M. Body mass index and marijuana use. J Addict Dis. 2005;24:95-100.

62. Danielsson AK, Lundin A, Yaregal A, et al. Cannabis use as risk or protection for type 2 diabetes: a longitudinal study of 18,000 Swedish men and women. J Diabetes Res. 2016;2016:6278709.

63. Hayatbakhsh MR, O'Callaghan MJ, Mamun AA, et al. Cannabis use and obesity and young adults. Am J Drug Alcohol Abuse. 2010;36: 350-356.

64. Waterreus A, Di Prinzio P, Watts GF, et al. Metabolic syndrome in people with a psychotic illness: is cannabis protective? Psychol Med. 2016;46: 1651-1662.

65. Huang DY, Lanza HI, Anglin MD. Association between adolescent substance use and obesity in young adulthood: a group-based dual trajectory analysis. Addict Behav. 2013;38:2653-2660.

66. Mittleman MA, Lewis RA, Maclure $M$, et al. Triggering myocardial infarction by marijuana. Circulation. 2001;103:2805-2809.

67. Sabia JJ, Swigert J, Young T. The effect of medical marijuana laws on body weight. Health Econ. 2017;26:6-34.

68. Levendal RA, Schumann $D$, Donath $M$, et al. Cannabis exposure associated with weight reduction and $\beta$-cell protection in an obese rat model. Phytomedicine. 2012;19:575-582.

69. Le Foll B, Trigo JM, Sharkey KA, et al. Cannabis and $\Delta$ 9tetrahydrocannabinol (THC) for weight loss? Med Hypotheses. 2013;80: 564-567.

70. Rodondi N, Pletcher MJ, Liu K, et al. Marijuana use, diet, body mass index, and cardiovascular risk factors (from the CARDIA study). Am J Cardiol. 2006;98:478-484.

71. Smit $E_{1}$ Crespo CJ. Dietary intake and nutritional status of US adult marijuana users: results from the Third National Health and Nutrition Examination Survey. Public Health Nutr. 2001:4:781-786.

72. Ngueta G, Bélanger RE, Laouan-Sidi EA, et al. Cannabis use in relation to obesity and insulin resistance in the inuit population. Obesity. 2015;23. 290-295.

73. Foltin RW, Fischman MW, Byrne MF. Effects of smoked marijuana on food intake and body weight of humans living in a residential laboratory. Appetite. 1988;11:1-14

74. Pagotto $U$, Marsicano $G$, Cota $D$, et al. The emerging role of the endocannabinoid system in endocrine regulation and energy balance. Endocr Rev. 2006:27:73-100.

75. Borgen LA, Lott GC, Davis WM. Cannabis-induced hypothermia: a doseeffect comparison of crude marihuana extract and synthetic 9tetrahydrocannabinol in male and female rats. Res Commun Chem Pathol Pharmacol. 1973;5:621-626.

76. Dol-Gleizes F, Paumelle R, Visentin V, et al. Rimonabant, a selective cannabinoid CB1 receptor antagonist, inhibits atherosclerosis in LDL receptor-deficient mice. Arterioscler Thromb Vasc Biol. 2009;29: 12-18.

77. D'Souza DC, Cortes-Briones JA, Ranganathan M, et al. Rapid changes in cannabinoid 1 receptor availability in cannabis-dependent male subjects after abstinence from cannabis. Biol Psychiatry Cogn Neurosci Neuroimaging. 2016;1:60-67.

78. Hirvonen J, Goodwin RS, Li C-T, et al. Reversible and regionally selective downregulation of brain cannabinoid CB1 receptors in chronic daily cannabis smokers. Mol Psychiatry. 2012;17:642-649.

79. Dudok B, Barna L, Ledri M, et al. Cell-specific STORM super-resolution imaging reveals nanoscale organization of cannabinoid signaling. Nat Neurosci. 2015;18:75-86.

80. Bonnet U, Preuss UW. The cannabis withdrawal syndrome: current insights. Subst Abuse Rehabil. 2017;8:9-37

81. Fryar CD, Carroll MD, Ogden CL. Prevalence of overweight, obesity, and extreme obesity among adults aged 20 and over: United States, 19601962 through 20132014. 2016. Available at: https://www.cdc.gov/nchs/ data/hestat/obesity_adult_15_16/obesity_adult_15_16.htm (accessed December 11, 2018) 
82. Muller T, Demizieux L, Troy-Fioramonti S, et al. Overactivation of the endocannabinoid system alters the anti-lipolytic action of insulin in mouse adipose tissue. Am J Physiol Endocrinol Metab. 2017;313:E26-E36.

83. Katz G, Lobel T, Tetelbaum A, et al. Cannabis withdrawal-a new diagnostic category in DSM-5. Isr J Psychiatry Relat Sci. 2014;51:270-275.

84. American Psychiatric Association. DSM V, Diagnostic and Statistical Manual of Mental Disorders. American Psychiatric Association: Washington, DC, 2013.

85. Alshaarawy O, Anthony JC. Cannabis smoking and diabetes mellitus results from meta-analysis with eight independent replication samples. Epidemiology. 2015;26:597-600.

86. Penner EA, Buettner $\mathrm{H}$, Mittleman MA. The impact of marijuana use on glucose, insulin, and insulin resistance among US adults. Am J Med. 2013;126:583-589.

87. Thompson CA, Hay JW. Estimating the association between metabolic risk factors and marijuana use in US adults using data from the continuous National Health and Nutrition Examination Survey. Ann Epidemiol. 2015;25:486-491.

88. Yankey BN, Strasser S, Okosun IS. A cross-sectional analysis of the association between marijuana and cigarette smoking with metabolic syndrome among adults in the United States. Diabetes Metab Syndr. 2016;10:S89-S95.

89. Bancks MP, Pletcher MJ, Kertesz SG, et al. Marijuana use and risk of prediabetes and diabetes by middle adulthood: the Coronary Artery Risk Development in Young Adults (CARDIA) study. Diabetologia. 2015;58: 2736-2744.

90. Velasco G, Sánchez C, Guzmán M. Towards the use of cannabinoids as antitumour agents. Nat Rev Cancer. 2012;12:436-444.

91. Clark TM. Cannabis use is associated with a substantial reduction in premature deaths in the United States. 2017. Available at: https:// scholarworks.iu.edu/dspace/handle/2022/21632 (accessed December 11, 2018).

92. Eubanks LM, Rogers $C J$, Beuscher $A E$, et al. A molecular link between the active component of marijuana and Alzheimer's disease pathology. Mol Pharm. 2006;3:773-777.

93. Cao C, Li Y, Liu H, et al. The potential therapeutic effects of THC on Alzheimer's disease. J Alzheimers Dis. 2014;42:973-984.

94. Currais A, Quehenberger O, Armando AM, et al. Amyloid proteotoxicity initiates an inflammatory response blocked by cannabinoids. NPJ Aging Mech Dis. 2016;2:16012.

95. Ramírez BG, Blázquez C, Gómez del Pulgar TG, et al. Prevention of Alzheimer's disease pathology by cannabinoids: neuroprotection mediated by blockade of microglial activation. J Neurosci. 2005;25:19041913.

96. Bedse G, Romano A, Lavecchia AM, et al. The role of endocannabinoid signaling in the molecular mechanisms of neurodegeneration in Alzheimer's disease. J Alzheimers Dis. 2015;43:1115-1136.

97. Reis JP, Auer R, Bancks MP, et al. Cumulative lifetime marijuana use and incident cardiovascular disease in middle age: the Coronary Artery Risk Development in Young Adults (CARDIA) study. Am J Public Health. 2017 107:601-606.

98. Cerdá M, Moffitt TE, Meier MH, et al. Persistent cannabis dependence and alcohol dependence represent risks for midlife economic and social problems: a longitudinal cohort study. Clin Psychol Sci. 2016;4: 1028-1046.

99. Meng H, Liu Y, Lai L. Diverse ways of perturbing the human arachidonic acid metabolic network to control inflammation. Acc Chem Res. 2015;48: 2242-2250.

100. Franz CA, Frishman WH. Marijuana use and cardiovascular disease. Cardiol Rev. 2016;24:158-162.

101. Boehnke KF, Litinas $\mathrm{E}$, Clauw DJ. Medical cannabis use is associated with decreased opiate medication use in a retrospective cross-sectional survey of patients with chronic pain. J Pain. 2016;17:739-744.

102. Bradford AC, Bradford WD. Medical marijuana laws reduce prescription medication use in medicare part D. Health Aff (Millwood). 2016;35: 1230-1236.

103. Bradford AC, Bradford WD, Abraham A, et al. Association between US state medical cannabis laws and opioid prescribing in the Medicare Part D population. JAMA Intern Med. 2018;178:667-672.

104. Haroutounian S, Ratz Y, Ginosar Y, et al. The effect of medicinal Cannabis on pain and quality-of-life outcomes in chronic pain: a prospective open-label study. Clin J Pain. 2016;32:1036-1043.

105. Bachhuber MA, Saloner B, Cunningham CO, et al. Medical cannabis laws and opioid analgesic overdose mortality in the United States, 19992010. JAMA Intern Med. 2014;174:1668-1673.

106. Lucas P, Walsh Z. Medical cannabis access, use, and substitution for prescription opioids and other substances: a survey of authorized medical cannabis patients. Int J Drug Policy. 2017;42:30-35.

107. Lucas $P$, Reiman A, Earleywine $M$, et al. Cannabis as a substitute for alcohol and other drugs: a dispensary-based survey of substitution effect in Canadian medical cannabis patients. Addict Res Theory. 2013 21:435-442.

108. Wen $\mathrm{H}$, Hockenberry JM. Association of medical and adult-use marijuana laws with opioid prescribing for Medicaid enrollees. JAMA Intern Med. 2018:178:673-679.

109. Jones CM, Mack KA, Paulozzi LJ. Pharmaceutical overdose deaths, United States, 2010. JAMA. 2013;309:657-659.

110. Gerberich SG, Sidney S, Braun BL, et al. Marijuana use and injury events resulting in hospitalization. Ann Epidemiol. 2003;13:230-237.

111. Le Strat $Y$, Le Foll B. Obesity and cannabis use: results from 2 representative national surveys. Am J Epidemiol. 2011;174:929-933.

112. Barry D, Petry NM. Associations between body mass index and substance use disorders differ by gender: results from the National Epidemiologic Survey on Alcohol and Related Conditions. Addict Behav. 2009;34:51-60

Cite this article as: Clark TM, Jones JM, Hall AG, Tabner SA, Kmiec RL (2018) Theoretical explanation for reduced body mass index and obesity rates in Cannabis users, Cannabis and Cannabinoid Research 3:1, 259-271, DOI: 10.1089/can.2018.0045.

Abbreviations Used
$2-\mathrm{AG}=2$-arachidonoylglycerol
$\mathrm{AEA}=$ anandamide; $N$-arachidonoylethanolamide
$\mathrm{ALA}=\alpha$-linolenic acid
$\mathrm{AOR}=$ adjusted odds ratio
$\mathrm{BMI}=$ body mass index
$\mathrm{CB}_{1} \mathrm{R}=$ Cannabinoid receptor 1
$\mathrm{CB}_{2} \mathrm{R}=$ Cannabinoid receptor 2
$\mathrm{CNS}=$ central nervous system
$\mathrm{DM}=$ diabetes mellitus
$\mathrm{DSM}-\mathrm{V}=$ Diagnostic and Statistical Manual of Mental
$\mathrm{DS} \mathrm{Disorders,}$ 5th Edition
$\mathrm{DS}-\mathrm{IV}=$ Diagnostic and Statistical Manual of Mental
$\mathrm{eCB}=$ Disorders, 4 th Edition
$\mathrm{FA}=$ fatty acid
$\mathrm{LA}=$ linoleic acid
$\mathrm{MI}=$ myocardial infarction
$\mathrm{THC}=\Delta^{9}$-tetrahydrocannabinol

Publish in Cannabis and Cannabinoid Research

Cannabis and Cannabinoid Research

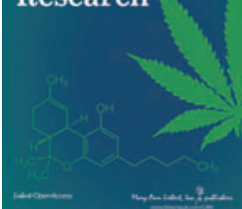

- Immediate, unrestricted online access

- Rigorous peer review

- Compliance with open access mandates

- Authors retain copyright

- Highly indexed

- Targeted email marketing 